\title{
Instructional practices affecting learner engagement in blended learning environments
}

\author{
Semiral Öncü* \\ Department of Computer Education and Instructional Technologies, Necatibey Faculty of \\ Education, Balıkesir University, Balıkesir, Turkey \\ ORCID: 0000-0001-8549-094X
}

\author{
Barbara A. Bichelmeyer \\ School of Education \& Human Sciences, The University of Kansas, Lawrence, KS, \\ United States
}

ORCID: 0000-0001-6035-575X

Article history

Received:

19.12.2020

Received in revised form: 26.01.2021

Accepted:

01.02 .2021

Key words:

Engagement, Active learning,

Collaboration, Instructional method, Instructional practice
Learners have to engage in academically purposeful instructional endeavors to be successful in school. Latest research indicates that the learners of today are not as interested in educational deeds as they need to be. Educational stakeholders should look for means to address this tendency to have a positive influence on educational results. This study explores the instructional practices that play a role in behavioral engagement (also known as involvement) of learners in schoolwork in the Cisco Certified Network Associate (CCNA) program - an information technology certificate program. Behavioral engagement in this context refers to learners' active learning and collaboration with peers. A twolevel hierarchical linear modeling was established to predict behavioral engagement from instructional practices while controlling for certain learner level (expectancy and value motivation, gender, and age) and teacher level (teaching and networking experience) variables. Learners who attended the CCNA program in the United States, totaling 773 high school and community college students, were matched specifically with 149 teachers who taught them. Student and instructor surveys were conducted online to gather data. The results show that the level of learner involvement in the program was poor, equivalent to the national student engagement survey of the period. However, if their teachers used collaborative and learner-centered practices, learners were more involved in schoolwork behaviorally. Learners were also very involved in the program if they placed a high value on the program. Female learners were not as active as male learners. In addition to the two instructional practices implied in this study, another major takeaway is that learners should be advised as early as possible about the detrimental impact of poor motivation in the program.

\footnotetext{
*Correspondency: semiral@gmail.com
} 


\section{Introduction}

Student success and career development can be significantly predicted from student engagement (Astin, 1993; Baker, Spiezio, \& Boland, 2004; Kuh, 2003; Pascarella \& Terenzini, 1991). Students' attendance at school (Spady, 1970; Tinto, 1975) and achievement (Chaves, 2003; Pintrich \& Schunk, 1996) are highly dependent on their being involved in schoolwork.

The significance of any learning-related activity can be assessed on the basis of its influence on learner achievement. But the problem with the highest significance in terms of urgency and persistency that should concern teachers and students is not poor learner achievement but rather poor engagement (Newmann, 1992). It is a struggle in contemporary educational settings to get students participate in scholarly activities in such a way that productive learning is feasible. Students too often get sidetracked by events taking place in everyday life around them. Among those that can easily divert learners from concentrating on a matter are the growing prevalence of careers in addition to recent evolution in digital technologies. They ignore aspirations relating to their postgraduate careers or to their potential goals in certain other situations (Schneider \& Stevenson, 1999). In some other cases, they appear to have no enthusiasm and do not play a more energetic role (McKeachie, 1994). Ideas may be broadened, but the argument is that it makes no sense to expect decent educational outcomes if students do not actively participate in lessons in the first place. That is why, student engagement is an essential educational reference point for achievement (Willms, 2003), incentivizing the exploration of methods for the participation of students in academic work.

Instructional practices, a main concern of instructional designers, are latent instruments to manipulate learners' engagement. As an alternative to conventional educational settings, and with growing presence, blended learning also provides great advantages for students. But the manipulation of instructional practices in blended learning with regard to their implications on learner engagement has not received much interest, although it deserves far more.

Inspired by these motives, the aim in this research study was to explore to what extent the instructional practices in the Cisco Certified Networking Associate (CCNA) program, which is a well-structured, standards-oriented, blended learning environment, were associated with learner engagement.

Many research studies have explored the quality of learner engagement in light of instructional techniques (Ahlfeldt, Mehta, \& Sellnow, 2005; Bujod \& Saint-Pierre, 1996; Roadrangka \& Yeany, 1985; Shernoff, Csikszentmihalyi, Schneider, \& Shernoff, 2003; Umbach \& Wawrzynski, 2005). Lecturing, for instance, has unfailingly been associated with poor learner engagement (Roadrangka \& Yeany, 1985). Delialioğlu (2012) reported that lecture-based lessons were less superior to problem-based lessons in terms of inducing university students' active learning and time on task in the blended learning environment. Similarly, Craft and Capraro (2017) linked science, technology, engineering, and mathematics-oriented problem-based learning lessons for middle school students with increased academic engagement — but not with behavioral engagement. In that same vein, Prata, Festas, Oliveira, and Veiga (2019) studied 14-to-17-old learners' engagement in lecture-based writing versus cooperative writing programs and reported that the latter yielded better behavioral and affective engagement. Research on medical students also associate problem-based learning (Ozgonul \& Alimoglu, 2019) and team (Kelly et al., 2005; Ozgonul \& Alimoglu, 2019) learning with more engaged students than lecture-based learning. 
More recent research tries to seek causation between student engagement and more contextspecific instructional practices. Yu, Jiang, and Zhou (2020), for instance, investigated college and university students' motivation and engagement as impacted by three different instructional approaches: product-, process-, and genre-oriented writing. They ranked the approaches respectively as well from worst to best in terms of their contribution to adaptive motivation and engagement in writing. D'Aquila, Wang, and Mattia (2019) examined the effectiveness of using instructional videos on Youtube as an instructional strategy in traditional and hybrid (blended learning) environments, and associated student engagement with the frequency of viewing videos. They concluded that students in hybrid courses more frequently viewed videos. Alioon and Delialioğlu (2019) have shown that implementing iteratively updated mobile-learning activities that are supported with increased teacher feedback and that heavily rely on student information sharing improve students' collaborative-learning behavior and their interaction with faculty — as indicators of student engagement.

Most such studies indicate that learner engagement can be estimated from instructional practices applied in lectures. But the association between instructional practices and learner engagement in blended learning has been investigated by only some of these studies, and none of them to the extent of the present study.

\section{Instructional Practices \& Engagement}

There are varying findings on how instructional practices affect engagement. Greenwood, Horton, and Utley (2002) provide examples of a number of instructional contexts in the classroom relevant to learner engagement, where instructional activities that enable learners to pay direct attention enhance learner engagement. Such activities would involve learning using paper and pencil and instructional materials that list questions or tasks for students. There is minimal engagement if the focus in the lesson turns towards other learners or the instructor as in during lectures and classroom discussions. In a similar way, how learners are organized into groups is also important. Independently working learners appear to be more engaged in lessons than those who study in whole-class settings. In addition, engagement is strengthened when students get attention from their teachers individually. However, practices such as transitions between instructional events or tasks that have no educational purpose facilitate limited learner engagement.

Fredricks, Blumenfeld, and Paris (2004) claim that learners are more engaged if they work on "tasks that (a) are authentic; (b) provide opportunities for students to assume ownership of their conception, execution, and evaluation; (c) provide opportunities for collaboration; (d) permit diverse forms of talents; and (e) provide opportunities for fun" (p. 79). In the same vein, "authentic and challenging tasks are associated with higher behavioral, emotional, and cognitive engagement" (Fredricks et al., 2004, p. 79). Not only instructor practices, but also learner perceptions in that manner matter. The degree of participation of learners can be estimated from their perceptions of the extent to which they take part in authentic lessons (Marks, 2000). Furthermore, engagement can possibly be improved if learners study in teams on personally meaningful everyday tasks (Helme \& Clarke, 2001) and if they work together with other students (Alioon \& Delialioğlu, 2019; Guthrie \& Wigfield, 2000).

\section{An Instructional Practice Framework}

This study focuses on eleven separate instructional methods that are practiced and monitored in the CCNA program: demonstration, hands on activities, individual student work, 
lecture, online simulations/games, reviewing homework, reviewing test results, small group work, learner presentations, testing, and classroom discussions. It is challenging and may be too unsophisticated to compare to each of these methods from the literature separately, since researchers often reference them either in broad terms or in very particular settings, making it difficult to generalize them to other contexts. It is also necessary to consider not analyzing these instructional practices in an isolated fashion on the basis of the parameters concurrently involved in statistical analyses. Count-wise, the involvement of many instructional practices makes it imperative to include a large number of research participants in order to conduct a satisfactory analysis, which is not always feasible. Reducing the number of instructional practices by grouping them together in this sense also makes it easy to interpret the data. For these reasons, a framework suggested by Reigeluth and Moore (1999) was employed in the present study. Their framework provides six perspectives for the consideration and comparison of instructional methods: (1) Type of learning, (2) control of learning, (3) focus of learning, (4) grouping for learning, (5) interactions for learning, and (6) support for learning.

The type of learning is about the extent to which instructional methods are about information memorization, application of skills, understanding relationships, or application of generic skills. The focus of learning concerns the content's being a topic, problem, or domain, or its being an interdisciplinary issue. Since these two practices are specifically about instructional content, and since the CCNA curriculum has uniform instructional content for all classrooms and schools, the two perspectives are not as handy for comparison as the remaining four perspectives. So, these two perspectives were excluded, and the remaining four were used to organize the instructional practices explored in this study.

The interactions for learning perspective makes it possible to assess whether a certain instructional practice can be considered to involve interaction between the learner and other instructional components - i.e., other students, the teacher, the tools, the information or the environment/manipulatives - and to assign the practice into one. The remainder of the perspectives are each portrayed by Reigeluth and Moore as having a scale graded from one extent to the other. For instance, the teacher-centered activities are towards one side of the scale while the learner-centered activities are towards the other side with respect to the control of learning perspective.

The support for learning perspective is about cognitive and emotional support. The latter weighs instructional methods in terms of having qualities that inspire learners, support their emotions, and so on. While a number of instructional practices may be identified with cognitive support in the CCNA program, it is not practicable to equate them with emotional support since the latter typically requires personal efforts of teachers. Additionally, the degree of emotional support provided by teachers to learners is unknown due to the technique the practices are measured in the CCNA program. For this reason, with respect to the support for learning, instructional practices were assessed according to cognitive support only.

Figure 1 presents the perspectives in rows and the instructional practices in columns, where each intersection point corresponds to a scale. The filled rectangles each refer to the degree of the instructional practice on that scale through the relevant perspective. The legend for instructional practices is provided at the right side of the figure. As explained previously, three of the perspectives have continuous scales, ranging from the least to the most, and the interactions for learning has a scale consisting of five categories.

It may be useful to explain the figure through an example. If learner presentations are 
implemented in a lesson, typically learners decide on the instructional content, while the teacher has control over the types of content that learners can present. It is the responsibility of the learner to select the content of the presentation, to arrange it in a coherent fashion, and to deliver it. The student (often) briefly assumes charge of the lesson in most circumstances and determines who can make comments or who can direct questions. That is why learner presentations are represented by a rectangle that is close to "student centered," referring to a superior level of student control in Figure 1. Learner presentations can take place in full-class sessions as well as in small groups, so "grouping for learning" highlights both settings. With regard to the "interactions for learning," through learner presentations, learner-teacher and learner-learner interactions can be achieved.

The principles for organizing practices are not straightforward; the methods used may differ from one teacher to another, but an overall analysis shows the structure in Figure 1, where the practices with analogous attributes were brought together. Dashed lines correspond to the common features surfacing among the practices, highlighting the most noteworthy relationships among practices. These relationships indicate a classification of four broad categories, which were given informative names in Figure 1: teacher-centered, learnercentered and collaborative practices, and feedback. INSTRUCTIONAL PRACTICES

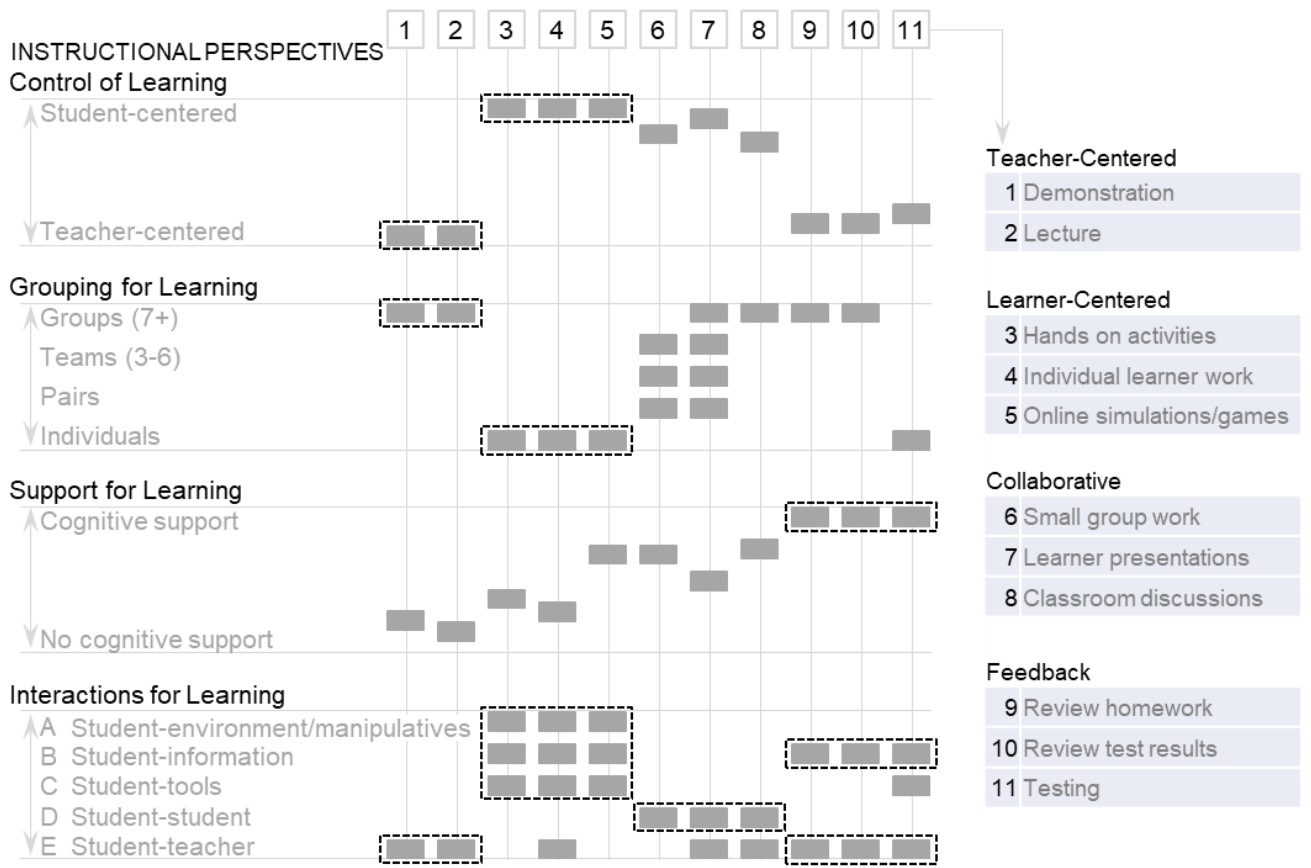

Figure 1. Categorization of instructional practices based on the comparison framework of Reigeluth and Moore (1999)

Demonstration and lecture are given by the teacher and delivered to an entire classroom of students. While the interaction that takes place in the classroom can be described as an interaction between student and teacher, it is in most cases one-directional where the teacher is the prevailing character. These practices were brought together and named teacher-centered practices due to the heavy presence of the teacher.

Hands-on activities, individual student work, and online simulations/games have a number of commonalities. These three practices suggest that the student studies the instructional material independently. Contingent upon the nature of the content of the instruction, students interact 
with tools, information, and the settings in all three of the practices. Since these exercises highlight the role of students in their personal learning, they are named learner-centered practices.

Three other practices, small-group work, learner presentations, and classroom discussions, have in common the interaction factor between learners. These practices - even though they have certain differences - foster independence and peer cognitive support. They enable learners to study in groups or as a class, debate their thoughts, express and address them, so they are named collaborative practices.

The last grouping — reviewing homework, reviewing test results, and testing — are for learners to validate their education and refer to supporting them cognitively at an elevated level. All three practices require learners to communicate with the teacher since the teacher is typically the one to validate the performance done by the learners. This practice category was therefore named feedback.

If instructional practices can help estimate learner engagement, specific instructional approaches can be encouraged to enhance various attributes of engagement and thereby improve learning. In addition, every educator would agree with the supposition that lessons with active learners are more fun experience for both learners and teachers. Therefore, teachers should look for opportunities to get their students involved as much as possible. To that end, understanding the connection between instructional practices and engagement can encourage teachers to enhance their classes. It can allow instructional designers to develop more powerful instructional settings, thereby enhancing instructional systems technology strategies and, ultimately, boosting learning and achievement. So, this study focused on answering the following research question:

How do instructional practices affect learner engagement? Specifically, are there practices that facilitate active learning and collaboration? And, if so, how do the practices contribute to learner engagement?

\section{Method}

This research was carried out by using data gathered through the Cisco Networking Academy Evaluation Project (CNAEP) at Indiana University. CCNA offers a blended learning environment where courses are provided to learners online and have a standard curriculum delivered across many institutions. Course content is delivered by teachers in physical classes. The program has four courses on networking mostly completed one after another. At universities, the courses are offered altogether in two academic terms (e.g., CCNA 1-2 and CCNA 3-4).

The program teaches networking education. The courses cover switch and router installation for computer networking, troubleshooting simple networking issues, enhancing performance, and dealing with problems with network security. What is learned in the courses comprises hardware as well as software topics in varying levels of networks.

\section{Research Design}

Five data sources through the CNAEP were used to conduct the present study: CCNA 1 Student Survey, CCNA 2 Student Survey, Instructor Survey, CCNA 1 Student Demographics, and CCNA 2 Student Demographics. Figure 2 demonstrates the timeline of all 
student surveys conducted in relation to the courses (not all surveys were utilized in this study). All data were pooled and analyzed together to estimate learner engagement.

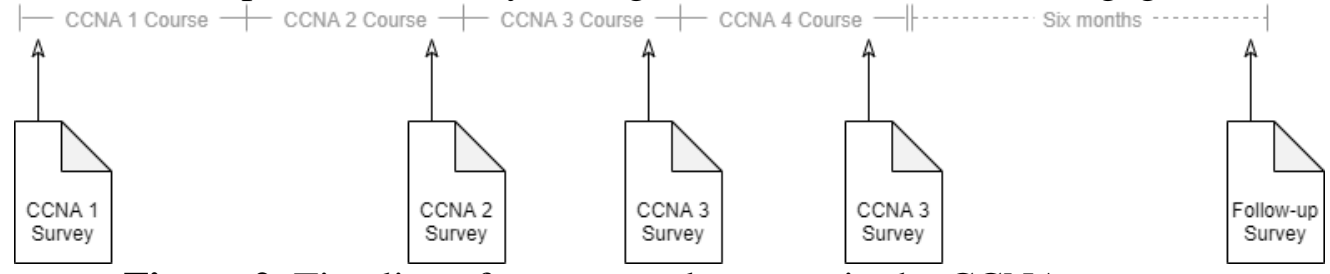

Figure 2. Timeline of courses and surveys in the CCNA program

Students of the program take a survey designed by the CNAEP before they begin the CCNA 1 course and after they finish each of the remaining three courses. Except for the first survey, surveys are administered after half of the duration of the course. The surveys may include questions on the course in question or about the overall program. Questions regarding motivation and engagement are included in the CCNA 1 and CCNA 2 Student Surveys, respectively.

Each CCNA course presented in Figure 2 includes learner demographic information in records as well. Gender and age information for learners were extracted from the CCNA 1 and 2 records, since only their surveys were utilized in the present study.

CCNA teachers are also requested to participate in a survey about the program, where they are also asked about the practices they implement in the program and information about their demographics. Their data can be associated with learner data.

Instructional practices implemented by one teacher can be considerably different from another teacher's practices. Typically, research studies of this type connect learner data to teacher data at the school level. In other words, all school practices are totaled, which makes it challenging or impossible to know what practices individual learners are exposed to. In this study, the learner data can be directly associated with the data of the teachers, so it is possible to determine the practices each student encountered.

\section{Participants}

The criteria for inclusion in this study as a learner was being a high school or a community college student, who took both the CCNA 1 and 2 courses and having filled out the corresponding surveys. The criteria for inclusion as a teacher was being a teacher who taught the corresponding CCNA courses and having filled out the Instructor Survey. These surveys are conducted all over the world, but learners and teachers from the United States only were explored in this study in order to eliminate the impact of any cultural differences brought by countries.

\section{Instruments}

While developing the surveys, CNAEP focused on identifying the elements affecting learner achievement or those likely to be impacted by the CCNA program. CNAEP incorporated items from various existing measurement instruments after piloting and modifications. Engagement items are inquired in the CCNA 2 and CCNA 3 surveys and come from the NSSE without any significant revisions. The instruments utilized in this study are described below. 


\section{Learner Engagement}

This study focused on active learning and collaboration as the learner behavioral engagement. Data regarding these engagement items were gathered as a scale through the CCNA 2 Student Survey, which was defined by Kuh (2002) in the NSSE. The scale was reported by Kuh (2002) to be reliable and valid for students studying at four-year universities. NSSE investigates overall experiences of college students; with a minimal revision, however, the CCNA 2 Survey requested from learners to rate their experience in the course by comparing it to a similar course they had taken previously.

The items regarding active learning and collaboration are based on the assumption that learners only learn to the extent that they engage in educationally meaningful activities, articulate and exercise what they learn, and work together with their peers. This factor was measured using five questions about the degree to which the learners participate in these activities. The questions had four-point Likert type options ranging from 1 = "very often" to 4 $=$ "never," which were later transformed to mean $1=$ "never" and $4=$ "very often." Questions involved items like "Asked questions in class or contributed to class discussions." The scale was mean scored and entered into the analyses. The coefficient alpha (Cronbach, 1951) reliability value from the CCNA 2 Student Survey was .71.

\section{Learner Motivation}

Motivation as a survey construct was measured through the CCNA 1 Student Survey. The items of the construct were drawn from the "Expectancy-Value Theory of Achievement Motivation" proposed by Wigfield and Eccles (2000). It has seven items, each focusing on a different motivation dimension. The two components constituting the construct, expectancy and value, refer to learners' expectations of the program in terms of their accomplishment and the value they give to the program. The construct included items like "How comfortable are you working with computers" and "How valuable are the Cisco courses to you," respectively. Answers were to be marked on a Likert scale of five points with options expressed in an adaptive manner that meant $1=$ "very unconfident" to $5=$ "very confident" for expectancy, and from $1=$ "not at all" to $5=$ "very much" for value. Mean scores for expectancy and value were calculated separately. Coefficient alpha (Cronbach, 1951) reliabilities measured from the CCNA 1 Student Survey were .73 and .83 , respectively.

\section{Learner Gender, Age, and Educational Level}

Gender and age data came from the CCNA 1 and 2 student demographics databases, and educational level came from the CCNA 2 Student Survey. Gender $(0=$ "male" and $1=$ "female") and educational level $(0=$ "high school" and $1=$ "community college") were categorical, and age was analyzed as a continuous variable.

\section{Instructional Practices}

Teachers were solicited through the Instructor Survey to put in descending order the six instructional practices they performed most often in a regular CCNA lesson or overall in the program. Each of the six activities had 12 options $(1=$ Demonstration, $2=$ Hands on activities, $3=$ Individual student work, $4=$ Lecture, $5=$ Online simulations/games, $6=$ Review homework, $7=$ Review test results, $8=$ Small group work, $9=$ Learner presentation, $10=$ Testing, $11=$ Classroom discussion, 12 = Other). The activities were stored in the database in six variables corresponding to the six activities. Each of the six variables except the "other" category - was later transformed to become a dummy variable 
corresponding to an instructional practice and could have a value of 1 or 0 referring to the existence or absence of the practice respectively. Finally, the resulting 11 variables were categorized under 4 broader categorical variables (teacher-centered, learner-centered, collaborative, and feedback) depending on the theory specified earlier.

\section{Teacher Characteristics}

There were two other factors about teachers corresponding to personal traits (Experience as a Networking Specialist and Teaching Experience). Data for them were collected via two questions in the Instructor Survey: "How many years have you worked fulltime as a networking specialist (not teaching)" $(1=$ No experience, $2=$ less than 1 year, $3=1$ $3,4=4-6,5=7-9,6=10-15,7=16-20,8=$ more than 20$)$; and "How many years have you taught a Cisco Networking Academy course" $(1=$ less than 1 year, $2=1,3=2,4=3,5=4,6$ $=5,7=6,8=7$ or more) ?

The variables to host networking and teaching experiences were transformed to be categorical: $0=$ "less than one year of networking experience" and $1=$ "one or more years of networking experience" (for networking); and $0=$ "less than three years of experience in teaching networking" and $1=$ "three or more years of teaching experience in networking" (for teaching).

\section{Statistical Analyses}

A Hierarchical Linear Modeling (HLM) analysis was conducted to determine elements estimating engagement (Figure 3). HLM is a method of analysis that - in addition to what multiple regression analysis has to offer in terms of analysis - specifically integrates the hierarchy-based nature of data into the design and prediction process. In multiple regression analyses, each predictive variable is assumed to have a potentially equal degree of contribution, with its specific function in describing the variable being estimated. Although multiple regression is a valuable statistical method in several circumstances, it lacks sophistication in the analysis of relationships stemming from categorical associations. In other words, the membership of subjects in a group may have certain extra impact on a dependent variable, and this is overlooked by multiple regression analyses. HLM is a method that can address this issue by classifying the elucidation of findings as per relevant hierarchy-based target subjects or groups. Because each instructional practice was used to teach a number of learners in this study, the learners were logically classified within the teacher, which prescribes HLM as one of the finest analytical methods for drawing inferences from the setting.

Two possible HLM levels can be suitable in the context of this study: level 1 and 2 - the learner and classroom (teacher) levels, respectively. Engagement, motivation, gender and age reside at level 1 and display variations among learners. Practices and teacher characteristics reside at level 2 as they concern classes of learners taught by the same teacher.

The multivariate analyses were carried out in HLM 6.0 (Raudenbush, Bryk, \& Congdon, 2006). Data were prepared in the SPSS (SPSS Inc.). As detailed previously, during this process, data were recoded and transformed as needed, and the teacher data were merged with the learner data. Variables with no meaningful zero were grand mean centered before being entered into the HLM analyses. All the statistics given reflect case-wise figures for each variable in the tables that are presented from this point on, except as otherwise specified. 


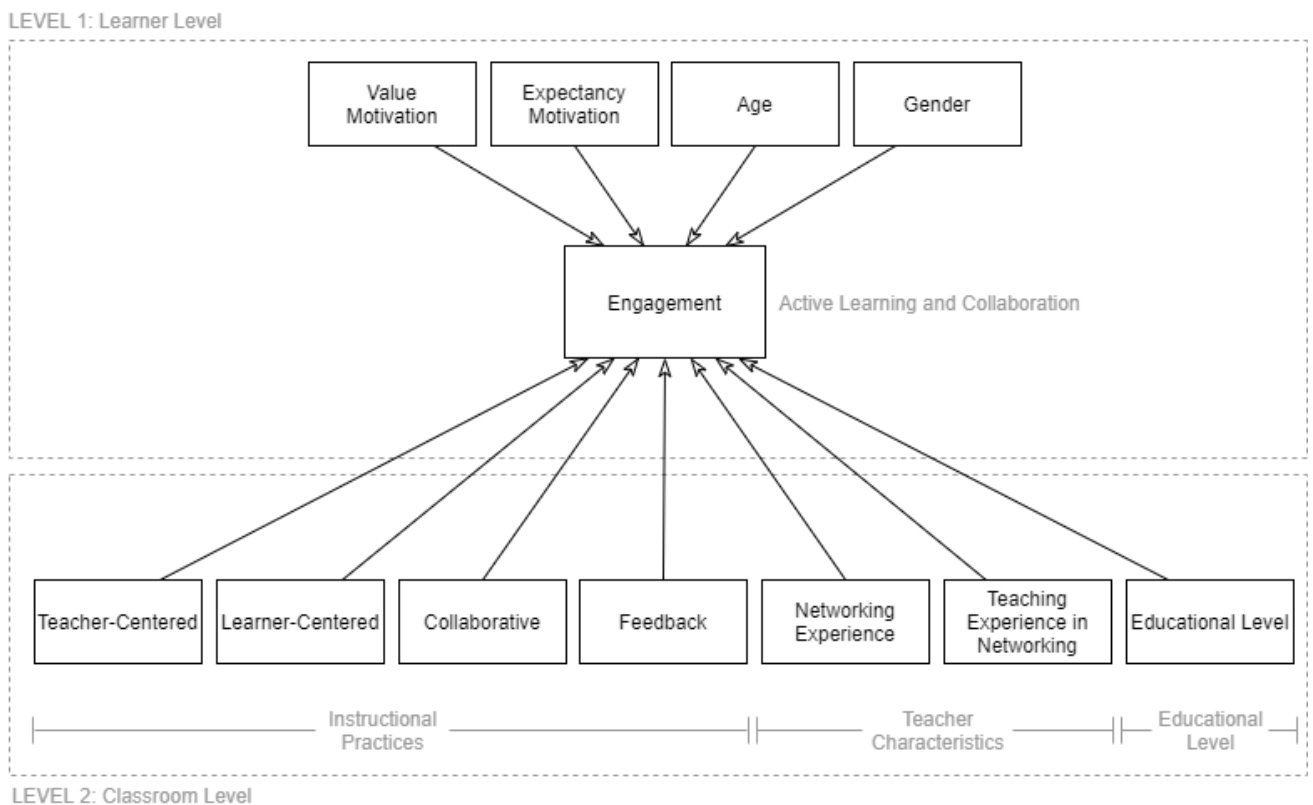

Figure 3. Factors predicting learner engagement: A hypothesized two-level regression model

Data suitable for HLM analysis were determined based on Snijder and Bosker (1993; 1999) and Maas and Hox (2005) to have at least $n=3$ cases at level 1 per level 2 unit. After elimination of cases with missing values, there were 773 students and 149 teachers. Table 1 shows the variables used to conduct the analyses in this study.

Table 1. Variables included in the HLM analyses

\begin{tabular}{|c|c|c|c|c|c|}
\hline \multirow[b]{2}{*}{ Variable } & \multirow[b]{2}{*}{ Definition } & \multirow{2}{*}{\multicolumn{2}{|c|}{ Type $(C / D)$ and Values }} & \multicolumn{2}{|c|}{ Observed } \\
\hline & & & & Min & $\operatorname{Max}$ \\
\hline \multicolumn{6}{|l|}{$\begin{array}{l}\text { Level } 1 \text { (Learner Level) } \\
\text { (L) }\end{array}$} \\
\hline \multicolumn{6}{|l|}{ Outcome } \\
\hline ENGAGEMENT & Active learning engagement & $C$ & $\begin{array}{l}1=\text { Never } \\
4=\text { Very often }\end{array}$ & 1.00 & 4.00 \\
\hline \multicolumn{6}{|l|}{ Predictors } \\
\hline M-EXPECTANCY & Expectancy motivation & $C$ & $\begin{array}{l}1=\text { Very difficult } * \\
5=\text { Very easy } *\end{array}$ & 1.33 & 5.00 \\
\hline M-VALUE & Value motivation & $C$ & $\begin{array}{l}1=\text { Not at all } \\
5=\text { Very much }\end{array}$ & 1.25 & 5.00 \\
\hline FEMALE & Gender & $D$ & $\begin{array}{l}0=\text { Male } \\
1=\text { Female }\end{array}$ & 0 & 1 \\
\hline AGE & Age & $C$ & In years & 15 & 60 \\
\hline \multicolumn{6}{|c|}{ Level 2 (Classroom Level) } \\
\hline INSTITUTION & Institution & $D$ & $\begin{array}{l}0=\text { High school } \\
1=\text { Community college }\end{array}$ & 0 & 1 \\
\hline T-CENTERED & Teacher-centered practices & $D$ & $\begin{array}{l}0=\text { Does not exist } \\
1=\text { Exists }\end{array}$ & 0 & 1 \\
\hline L-CENTERED & Learner-centered practices & $D$ & $\begin{array}{l}0=\text { Does not exist } \\
1=\text { Exists }\end{array}$ & 0 & 1 \\
\hline COLLABORATIVE & Collaborative practices & $D$ & $\begin{array}{l}0=\text { Does not exist } \\
1=\text { Exists }\end{array}$ & 0 & 1 \\
\hline FEEDBACK & Feedback practices & $D$ & $\begin{array}{l}0=\text { Does not exist } \\
1=\text { Exists }\end{array}$ & 0 & 1 \\
\hline N-EXPERIENCE & Networking experience & $D$ & $\begin{array}{l}0=\text { Less than a year } \\
1=\text { One or more years }\end{array}$ & 0 & 1 \\
\hline T-EXPERIENCE & Teaching experience in networking & $D$ & $\begin{array}{l}0=\text { Less than three years } \\
1=\text { Three or more years }\end{array}$ & 0 & 1 \\
\hline
\end{tabular}

$\mathrm{C}=$ Continuous, $\mathrm{D}=$ Dichotomous.

* While the options were articulated differently in each question, they ranged in meaning from difficult to easy. 


\section{Results}

Due to its professional orientation, the CCNA program is a program dominated by male students. Because of that, just about $11 \%$ of high school participants and $16 \%$ of community college participants are female in general.

In terms of the participants' educational levels, the data included in the analyses were virtually even. About $49 \%$ of the participants were high school students, and $51 \%$ of them were community college students. Descriptive statistics showed that males (2.29 \pm 0.62$)$ were found to be more engaged than females $(2.16 \pm 0.64)$ overall.

Table 2 presents results from descriptive statistics about level 1 and 2 variables, with listwise sizes of the sample $(\mathrm{N})$ below each level. These numbers correspond to the maximum number of units at level 1 (learners) and 2 (teachers) going into the HLM analysis.

The overall mean learner engagement (ENGAGEMENT) score including both school levels was $(2.27 \pm 0.62)$. With regard to the engagement scale, the midpoint for scores would be 2.50 . Considering that value, learners stated relatively low levels of participation in their coursework.

As seen in Table 2, with respect to M-EXPECTANCY, M-VALUE, and AGE, which were level 1 variables, learners from high schools and community colleges were somewhat different in terms of mean values. Mean values of learners from community colleges were greater than those from high schools in all three. Mean AGE would, of course, be greater in community colleges, but the other findings suggest that the learners from community colleges had slightly more motivation for doing coursework than those from high schools.

Some of the findings concerning level 2 variables also yielded diversities between the teachers of the two institutional types. For example, regarding networking experience, community college teachers were noticeably more experienced than high school teachers but teaching experience in networking did not differ from one school level to the other.

Table 2. Descriptive data on the variables included in the HLM

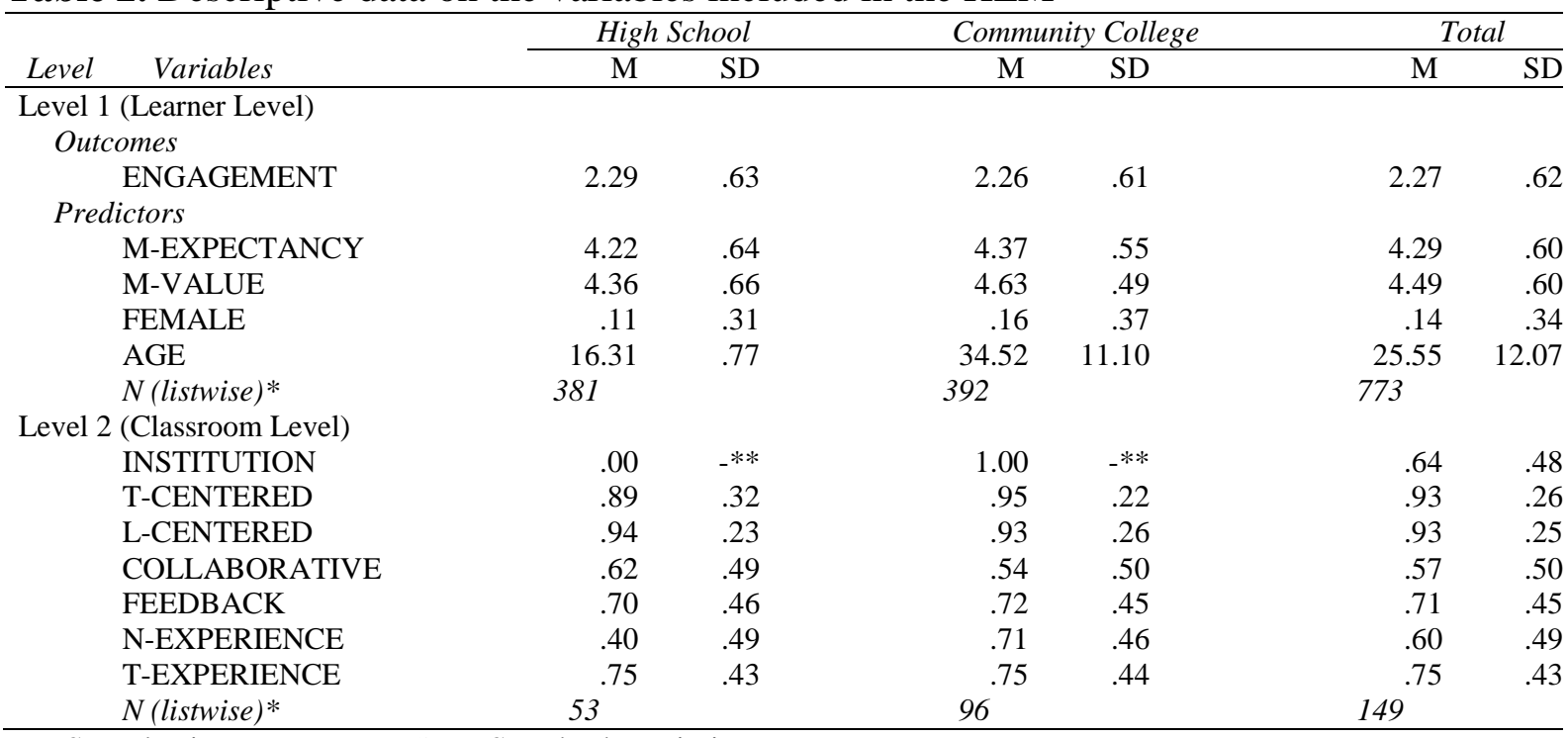

$N=$ Sample size; $M=$ Mean $S D=$ Standard Deviation

* Refers to the numbers included in the HLM analyses.

** Values in this cell are identical, so SD cannot be calculated. 
HLM models are typically created in a process made up of three phases. In order to be able to refer to them in this study, the phases are called base, step 1, and step 2, each of which has a learner level, a classroom (teacher) level, and a combined model. The last one is called combined as it is made up of a combination of the learner and teacher level models for the corresponding phase.

The analysis at the base model includes only the outcome variable. The analysis at step 1 additionally includes the level 1 variables. The analysis at step 2 further includes the level 2 variables.

\section{Base Model (Fully Unconditional Model)}

The base model delivers initial results to be employed as a basis for the upcoming models that are to be tested later on. This model characterizes a One-Way ANOVA with random effects, in which the grouping factor is the classrooms in the institutions. The results from this step reflect the distribution of the variation in outcome in terms of that originating from within classrooms and that originating from between classrooms.

According to the base model, the estimated grand engagement mean (which refers to the average score of all learners) was $\hat{\gamma}_{00}=2.26(\mathrm{t}=75.60, \mathrm{p}<.001)$, with a standard error $(S E)$ of .03 and a $95 \%$ confidence interval (CI) (Raudenbush \& Bryk, 2002). This implies that with $95 \%$ confidence, the active learning and collaboration had an estimated grand mean ranging from 2.20 and 2.32 .

The predicted variance of ENGAGEMENT at the learner $\left(\hat{\sigma}^{2}\right)$ and classroom $\left(\hat{\tau}_{00}\right)$ level were 0.34 and 0.046 , respectively. Based on the classroom level variance, the engagement scores at the classroom level were between 1.84 and 2.68 (Raudenbush \& Bryk, 2002). This indicated that there was a significant degree of variance in engagement levels among classrooms in the $\operatorname{program}\left(\chi^{2}=240.51, \mathrm{p}<.000\right)$.

Among the levels, $88.03 \%\left(p_{1}\right)$ of the total variance lies among students within classrooms, and $11.97 \%\left(p_{2}\right)$ lies among classrooms, based on calculations (Raudenbush \& Bryk, 2002).

\section{Step 1}

The estimated grand mean rose to $\hat{\gamma}_{00}=2.28$ as a result of the incorporation of the learner level predictor variables at step 1. This represents the fact that for a moderately motivated male learner at an average age considered as a reference, if all of the predictor variables at level 1 are held constant to be equal to 0 (zero), the learner would have an engagement score of 2.28 .

ENGAGEMENT was significantly predicted by M-VALUE and FEMALE. Female learners had an average engagement score that was 0.14 smaller than that of the male learners. A learner with a value motivation score that was 1 point greater than the mean M-VALUE score was 0.17 points more engaged than the student with a smaller value motivation score. This model at step 1 yielded a good model fit $\left(\chi^{2}=19.19, d f=4, p<.001\right)$ compared to that of the base model (Raudenbush \& Bryk, 2002). 


\section{Step 2}

Table 3 shows the step 2 results. Once the factors related to the classroom level were controlled, M-VALUE and FEMALE still significantly explained the variance in ENGAGEMENT scores. What is more, L-CENTERED and COLLABORATIVE, which were at the classroom level, also significantly explained ENGAGEMENT $(p<.05)$. Teachers' use of learner-centered and collaborative instructional practices resulted in learners having 0.23and 0.16-points higher engagement scores, respectively, than the use of other instructional practices. The estimated grand mean value $\left(\hat{\gamma}_{00}\right)$ also declined to 2.00 , compared to the value at step 1 .

The model fit at step 2 turned out to be better than the one at the base $\left(\chi^{2}=30.21, d f=11, p<\right.$ $.001)$, but not the one at step $1\left(\chi^{2}=11.02, d f=7, p>.05\right)$. The estimates based on Raudenbush and Bryk (2002) show that $2.57 \%\left(R^{2}\right)$ of the variance in engagement among learners in the population was explained by introducing the variables belonging to level 1 , and $7.82 \%\left(R^{2}\right)$ of the variance in average engagement among classrooms was explained by introducing the variables belonging to level 2 .

The results demonstrate that the models at step 1 and 2 have a better model fit if contrasted with the base. However, the model at step 1does not have a better fit than the model at step 2, which reflects that the step 1 and 2 models are successful in understanding the variance in engagement, while none is superior to the other.

Table 3. ENGAGEMENT results of the classroom level model

\begin{tabular}{|c|c|c|c|}
\hline Fixed Effect & Coefficient & se & $\overline{T \text {-ratio }}$ \\
\hline \multicolumn{4}{|l|}{ Model for classroom means } \\
\hline INTERCEPT, $\gamma_{00}$ & $2.00 *$ & .20 & 9.90 \\
\hline INSTITUTION, $\gamma_{01}$ & .04 & .08 & .53 \\
\hline T-CENTERED, $\gamma_{02}$ & .03 & .15 & .21 \\
\hline L-CENTERED, $\gamma_{03}$ & $.23^{*}$ & .11 & 2.11 \\
\hline COLLABORATIVE, $\gamma_{04}$ & $.16^{*}$ & .06 & 2.45 \\
\hline FEEDBACK, $\gamma_{05}$ & .04 & .06 & .61 \\
\hline N-EXPERIENCE, $\gamma_{06}$ & -.11 & .07 & -1.69 \\
\hline T-EXPERIENCE, $\gamma_{07}$ & -.07 & .05 & -1.28 \\
\hline M-EXPECTANCY, $\gamma_{10}$ & -.04 & .05 & -.79 \\
\hline M-VALUE, $\gamma_{20}$ & $.17 *$ & .05 & 3.31 \\
\hline FEMALE, $\gamma_{30}$ & $-.16^{*}$ & .07 & -2.36 \\
\hline AGE, $\gamma_{40}$ & .00 & .00 & -.56 \\
\hline
\end{tabular}

\begin{tabular}{lcrrr} 
Random Effect & $\begin{array}{c}\text { Variance } \\
\text { Component }\end{array}$ & $d f$ & $\chi^{2}$ & $p$-value \\
\hline Classroom mean, $u_{0 j}$ & .04587 & 141 & 228.09 & .000 \\
Level 1 effect, $r_{i j}$ & .33383 & & &
\end{tabular}

\begin{tabular}{lc}
\hline Deviance & 1401.97 \\
Estimated parameter count & 14 \\
\hline se $=$ standard error of estimate; $d f=$ degrees of freedom; $\chi^{2}=$ chi-square statistic \\
$* p<.05$
\end{tabular}




\section{Discussion and Conclusion}

This study has shown that there is considerable room for improvement in the engagement of learners in the program and that learners are significantly more engaged in academic work if they are taught through certain instructional practices, in line with the literature (Ahlfeldt et al., 2005; Greenwood et al., 2002; Roadrangka \& Yeany, 1985). Instructional practices are perhaps the most direct elements in instructional settings that can be used by practitioners to promote academic engagement.

Collaborative practices were the type of instructional practice that produced the most significant impact on learner engagement, or active learning and collaboration, when standardized. The instructional practice had a coefficient of about 0.16 points. It is possible to standardize the coefficients to assist in comparing the magnitudes of predictor variables through the following formula: $\gamma_{S T A N D A R D I Z E D}=\gamma \times S D_{X} / S D_{Y}\left(\gamma_{S T A N D A R D I Z E D}=0.16 \times\right.$ 0.50/0.62) (Snijders \& Bosker, 1999, p. 50). When standardized, collaborative instructional practices contribute about 0.13 points to engagement. In terms of unstandardized coefficients, if the teacher uses collaborative instructional practices, a male learner would be 0.16 points more engaged, if all other variables are held constant. This finding parallels the literature (Guthrie \& Wigfield, 2000; Shernoff et al., 2003; Umbach \& Wawrzynski, 2005) and implies that teachers striving to engage their learners more in their classrooms should resort to more collaborative practices. Collaborative practices include a group of more specific instructional practices as categorized in the context of this study: small-group work, learner presentations, and whole-class discussions. What these methods of instruction have in common is their propensity to demand more learner involvement, which is why they have been packed together. Such techniques also permit a greater degree of learner control over their learning.

As implied by the labels, the "collaborative" practice included as a predicting variable in the context of this study also had a "collaboration" counterpart (active learning and collaboration) in learner behavior that was employed as an outcome variable. This finding suggests that the methods carried out in the sense of collaboration have resulted in the anticipated outcome of learner behavior. In other words, the findings obtained from the learners and the teachers can be said to correlate and confirm the framework of learner engagement employed in this study.

Learner-centered practices also significantly estimated the extent to which learners would be engaged in coursework. In accordance with the literature (Shernoff et al., 2003), they were successful in reducing inert learner involvement and encouraging active learner participation and collaboration. Their unstandardized contribution ( 0.23 points) to learner engagement in the present study was superior when compared to the collaborative instructional practices. When the teacher uses learner-centered methods, a male learner would have an engagement score that is 0.23 points greater if all other variables are held constant. This corresponds to a contribution to the engagement score of around 0.09 points if taken as a standardized coefficient (Snijders \& Bosker, 1999).

Learner-centered instructional practices refer to hands-on learning, individual student work, and online simulations and games in the context of this study. What places these strategies in the same category is their advocacy for the utmost influence of learners over their own journey of learning. All these methods set the stage for learners to work individually. They require that learners deal with content, resources, and the environment independently. Along with collaborative instructional practices, these practices demonstrate and highlight the necessity for learning environments to empower learners and provide them with opportunities to work together. And they suggest downgrading the position of teachers as sources of 
information that govern the learning settings, as also advocated by the literature (Roadrangka \& Yeany, 1985; Shernoff et al., 2003).

In terms of the other classroom level variables in the study, teacher-centered instructional practices and feedback have not helped learners to be more engaged. With regard to the learner level variables, learners who were not motivated were not engaged in coursework either. It is important to recognize learners of this type early on and alert them of the possible consequences. Female learners were less engaged compared to male learners, but more frequent use of learner-centered methods may help transform the latent female involvement in the CCNA program and in blended learning environments of similar nature.

Increasingly capable learning management systems of today make it easy to focus attention on learners and help them work together online, but there are still challenges for students to feel that they are included, close to each other, as if working in the presence of each other. From this perspective, researchers should consider exploring the extent to which studentcentered and collaborative strategies can be incorporated into the instructional environment, while respecting the on-site and online proportion of instructional experience. The same is true for practitioners as well. They should maintain a balance between the near and distant parts of their courses in order to allow learners to have a great deal of control over their learning and work together, and to avoid making it too cumbersome for learners to do the same thing, requiring learners to tackle environmental challenges.

Regardless of the institutional level, blended learning in this context has had the same impact on learner engagement. While this means that instructional practices one can rely on at one institutional level can coherently be relied on at the other in this sense, there may be specific student-centered and collaborative techniques that are more successful in engaging learners, depending on the institutional level. As this study adopted an approach that combined certain instructional practices, future research can concentrate on the identification of such specific (individual) techniques.

\section{Acknowledgement}

This study has been derived from the corresponding author's dissertation study titled "The relationship between instructor practices and student engagement: What engages students in blended learning environments?"

\section{References}

Ahlfeldt, S., Mehta, S., \& Sellnow, T. (2005). Measurement and analysis of student engagement in university classes where varying levels of PBL methods of instruction are in use. Higher Education Research \& Development, 24(1), 5-20. doi:10.1080/0729436052000318541

Alioon, Y., \& Delialioğlu, Ö. (2019). The effect of authentic m-learning activities on student engagement and motivation. British Journal of Educational Technology, 50(2), 655668. doi:10.1111/bjet.12559

Astin, A. W. (1993). What matters in college? For critical years revisited. San Francisco, CA: Jossey-Bass.

Baker, K. Q., Spiezio, K. E., \& Boland, K. (2004). Student engagement: Transference of attitudes and skills to the workplace, profession, and community. The IndustrialOrganizational Psychologist, 42(2), 101-107. 
Bujod, N., \& Saint-Pierre, H. (1996). Style d'intervention pedagogique, relations affectives enseignants-etudiants et engagement par rapport a la matiere [Style of Pedagogic Intervention, Teacher-Student Affective Relations, and Engagement in Content Material]. Canadian Journal of Higher Education, 26(1), 75-107.

Chaves, C. A. (2003). Student involvement in the community college setting. ERIC digest (ED477911). Retrieved from https://files.eric.ed.gov/fulltext/ED477911.pdf

Craft, A. M., \& Capraro, R. M. (2017). Science, technology, engineering, and mathematics project-based learning: Merging rigor and relevance to increase student engagement. Electronic International Journal of Education, Arts, and Science (EIJEAS), 3(6), 140158.

Cronbach, L. J. (1951). Coefficient alpha and the internal structure of tests. Psychometrika, 16(3), 297-334. doi:10.1007/BF02310555

D'Aquila, J. M., Wang, D., \& Mattia, A. (2019). Are instructor generated YouTube videos effective in accounting classes? A study of student performance, engagement, motivation, and perception. Journal of Accounting Education, 47, 63-74. doi:10.1016/j.jaccedu.2019.02.002

Delialioğlu, Ö. (2012). Student engagement in blended learning environments with lecturebased and problem-based instructional approaches. Journal of Educational Technology \& Society, 15(3), 310-322. doi:10.2307/jeductechsoci.15.3.310

Fredricks, J. A., Blumenfeld, P. C., \& Paris, A. H. (2004). School engagement: Potential of the concept, state of the evidence. Review of Educational Research, 74(1), 59-109. doi:10.3102/00346543074001059

Greenwood, C. R., Horton, B. T., \& Utley, C. A. (2002). Academic engagement: Current perspectives in research and practice. School Psychology Review, 31(3), 328. doi:10.1080/02796015.2002.12086159

Guthrie, J. T., \& Wigfield, A. (2000). Engagement and motivation in reading. In M. Kamil \& P. Mosenthal (Eds.), Handbook ofreading research (Vol. 3, pp. 403-422). Mahwah, NJ: Lawrence Erlbaum.

Helme, S., \& Clarke, D. (2001). Identifying cognitive engagement in the mathematics classroom. Mathematics Education Research Journal, 13(2), 133-153. doi:10.1007/BF03217103

Kelly, P. A., Haidet, P., Schneider, V., Searle, N., Seidel, C. L., \& Richards, B. F. (2005). A comparison of in-class learner engagement across lecture, problem-based learning, and team learning using the STROBE classroom observation tool. Teaching and Learning in Medicine, 17(2), 112-118. doi:10.1207/s15328015tlm1702_4

Kuh, G. D. (2002). The National Survey of Student Engagement: Conceptual framework and overview of psychometric properties. Bloomington, IN: Indiana University Center for Postsecondary Research.

Kuh, G. D. (2003). What we're learning about student engagement from NSSE: Benchmarks for effective educational practices. Change, 35(2), 24-32. doi: $10.1080 / 00091380309604090$

Marks, H. M. (2000). Student engagement in instructional activity: Patterns in the elementary, middle, and high school years. American Educational Research Journal, 37(1), 153184. doi:10.3102/00028312037001153

McKeachie, W. J. (1994). Teaching tips strategies, research and theory for college and university teachers (9th ed.). Lexington, MA: D. C. Heath and Company.

Newmann, F. M. (Ed.) (1992). Student engagement and achievement in American Secondary Schools. New York, NY: Teachers College, Columbia University. 
Ozgonul, L., \& Alimoglu, M. K. (2019). Comparison of lecture and team-based learning in medical ethics education. Nursing Ethics, 26(3), 903-913. doi:10.1177/0969733017731916

Pascarella, E. T., \& Terenzini, P. T. (1991). How college affects students: Findings and insights from twenty years of research. San Francisco: Jossey-Bass.

Pintrich, P. R., \& Schunk, D. H. (1996). Motivation in education: Theory, research and applications. Englewood Cliffs, NJ: Prentice Hall Merrill.

Prata, M. J., Festas, I., Oliveira, A. L., \& Veiga, F. H. (2019). The impact of a cooperative method embedded in a writing strategy instructional program on student engagement in school. Revista de Psicodidáctica (English ed.), 24(2), 145-153. doi:10.1016/j.psicoe.2018.12.001

Raudenbush, S. W., \& Bryk, A. S. (2002). Hierarchical Linear Models: applications and data analysis methods (2nd ed.). Thousand Oaks: Sage Publications Inc.

Raudenbush, S. W., Bryk, A. S., \& Congdon, R. (2006). HLM 6.0 for Windows: Scientific Software International.

Reigeluth, C. M., \& Moore, J. (1999). Cognitive education and the cognitive domain. In C. M. Reigeluth (Ed.), Instructional-design theories and models: A new paradigm of instructional theory (Vol. 2, pp. 51-68). Mahwah, New Jersey: Lawrence Erlbaum Associates, Publishers.

Roadrangka, V., \& Yeany, R. H. (1985). A study of the relationship among type and quality of implementation of science teaching strategy, student formal reasoning ability, and student engagement. Journal of Research in Science Teaching, 22(8), 743-760. doi:10.1002/tea.3660220806

Schneider, B. L., \& Stevenson, D. (1999). The ambitious generation: America's teenagers, motivated but directionless. New Haven: Yale University Press.

Shernoff, D. J., Csikszentmihalyi, M., Schneider, B., \& Shernoff, E. S. (2003). Student engagement in high school classrooms from the perspective of flow theory. School Psychology Quarterly, 18(2), 158-176. doi:10.1007/978-94-017-9094-9_24

Snijders, T. A. B., \& Bosker, R. J. (1999). Multilevel analysis: An introduction to basic and advanced multilevel modeling. London: Sage Publications.

Spady, W. G. (1970). Dropouts from higher education: an interdisciplinary review and synthesis. Interchange, 1(1), 64-85.

Tinto, V. (1975). Dropout from higher education: A theoretical synthesis of recent research. Review of Educational Research, 45(1), 89-125. doi:10.3102/00346543045001089

Umbach, P. D., \& Wawrzynski, M. R. (2005). Faculty do matter: The role of college faculty in student learning and engagement. Research in Higher Education, 46(2), 153-184. doi:10.1007/s11162-004-1598-1

Wigfield, A., \& Eccles, J. S. (2000). Expectancy-value theory of achievement motivation. Contemporary Educational Psychology, 25(1), 68-81. doi:10.1006/ceps.1999.1015

Willms, J. D. (2003). PISA student engagement at school a sense of belonging and participation: Results from PISA 2000. Paris: Organisation for Economic Cooperation and Development (OECD).

Yu, S., Jiang, L., \& Zhou, N. (2020). The impact of L2 writing instructional approaches on student writing motivation and engagement. Language Teaching Research(OnlineFirst), 1362168820957024. doi:10.1177/1362168820957024 